\title{
Entre renovadores e reacionários: a recepção estética e política da obra de Nietzsche na imprensa brasileira no período de 1893 a 1945
}

Geraldo Dias*

\begin{abstract}
Resumo: Este artigo tem por objetivo apresentar dezoito textos sobre Nietzsche publicados na imprensa brasileira no período de 1893 a 1945 . Tais trabalhos mostram que dois fatores da cultura brasileira desse período orientam a leitura da obra do filósofo: a renovação estético-cultural e a reação político-religiosa. Os textos transcritos na sequência seguem a ordem cronológica de suas publicações.

Palavras-chave: Nietzsche - recepção - Brasil - imprensa - Jornal do Commercio - Gazeta de Notícias - Fon-fon - O Commercio - Almanaque do Garnier - América Brasileira - Jornal do Recife - A Noite - Diário de Notícias - A Manhã.
\end{abstract}

Como Nietzsche, todos exigimos que nos cantem um canto novo. Paulo Prado. Poesia Pau Brasil.1924.

O super-homem de Nietzsche, alma da filosofia heroica do nazismo e, até certo ponto, do fascismo, escapa aos quadros cristãos-democráticos do espírito ocidental. Diário Carioca, Camillo Avelino, RJ, 1939.

* Doutorando em Filosofia pela Universidade Federal de São Paulo (UNIFESP), São Paulo, Brasil. E-mail: ge.pdias@hotmail.com. 
Dias, G.

I

Desde o final do século XIX Friedrich Nietzsche "tem presença marcante na cultura brasileira. Nas artes plásticas, no teatro, na literatura, nas ciências humanas em geral, na política, para dizer o mínimo, seu pensamento faz-se sentir"l. Sua obra, desde então, tem sido às vezes tomada como algo incondicionado, que existe em si e por si, agindo sobre seus leitores por uma força própria que dispensaria explicações. Esse pressuposto tem repousado na convicção de que há certa virtude criadora no seu autor, muito misteriosa e pessoal; e mesmo quando desfeita pela análise, ainda assim permanece um pouco nos seus leitores, na medida em que se opõe às tentativas de definir os fatores que orientam as leituras de sua obra ${ }^{2}$ É, portanto, justamente para desfazer equívocos como este que o trabalho de recepção se impõe. Para tanto, a pesquisa de recepção procura investigar a filosofia de Nietzsche em diferentes contextos, a fim de revelar os fatores que orientam as leituras de sua obra no Brasil ${ }^{3}$.

Nessa direção, transcrevemos aqui alguns textos sobre Nietzsche publicados na imprensa brasileira no período de 1893 a 1945 que expressam, ora de forma visível, ora de maneira mais implícita, a predominância de dois fatores da cultura brasileira norteando as leituras de sua obra. Os fatores são, de um lado, a renovação estético-cultural em curso desde o final do século XIX, primeiro entre os autores germanistas, passando depois pelos pré-modernistas até, por fim, pelos autores do movimento modernista e, de outro lado, a reação político-religiosa mobilizada contra essa mesma renovação.

1SILVA JR, Ivo da, "Nietzsche e a cultura brasileira". In: Em busca de um lugar ao sol: Nietzsche e a cultura alemã. São Paulo: Discurso Editorial, 2007, p. 183.

2 Cf. "O escritor e o público". In: CANDIDO, Antônio. Literatura e sociedade. Rio de Janeiro, Ouro Azul, $12^{\circ}$ ed., 2011, p. 83.

3 Cf. Nietzsche: aqui e lá. Entrevista com Scarlett Marton. Por João Neto, in Revista Filosofia, Editora Escala (disponível em http://filosofiacienciaevida.uol.com.br/ESFI/Edicoes/75/artigo271728-3.asp).

86 | Cad. Nietzsche, São Paulo, v.36 n.1, p. 85-102, 2015. 
Os textos transcritos foram publicados na forma de poema, artigos, ensaios, resenhas e conferências. Pertencem a autores conhecidos e atuantes na cultura brasileira da época, como Araripe Júnior, Augusto dos Anjos, Fábio Luz, Elysio de Carvalho, João Ribeiro, Albertina Bertha, Lima Barreto, Renato Almeida, Evaristo de Morais Filho, Julio Erasmo, Padre Leonardo Mascello, Corrêa Velho, Ernani Reis, Padre Carlos Barromeu, Hamilton Barata, João Scapino, Cleto Seabra Veloso.

Quanto ao primeiro fator, a recepção estética, a seleção de textos é composta por trabalhos quase sempre engajados no projeto de renovação estético-cultural predominante a partir do movimento modernista; e, quanto ao segundo fator, a recepção político-religiosa, a seleção contempla textos que defendem o filósofo das apropriações políticas que corroborem governos autoritários, no Brasil e na Europa, e ainda com textos de caráter reacionário, no sentido de se contraporem à renovação em curso e tentarem retomar os valores tradicionais, associando as obras de Nietzsche a Hitler, Mussolini e Getúlio Vargas, às vezes a fim de legitimar suas políticas dominadoras e, ainda outras, a fim recusar e obscurecer o pensamento do filósofo. Noutras palavras, a grande polêmica de então se situa em torno da leitura das obras nietzschianas ora numa chave estético-renovadora, utilizadas como fonte inspiradora para grupos de intelectuais engajados num projeto de renovação das artes, da linguagem e da cultura brasileira em geral; ora numa chave político-reacionária, que se colocava contra as mudanças em curso, sendo então utilizadas como contraponto da reação político-religiosa preocupada em assegurar e conservar os valores da tradição espiritualista, a moral cristã, o nacionalismo ufanista, a honra à pátria e à família, e que sempre teima em relacionar sua obra com as guerras em curso na Europa desde o final do século XIX, a guerra franco-prussiana, a Primeira e a Segunda Guerra Mundial.

Como veremos, esses fatores comparecem de maneira expressiva na preferência por certos livros do filósofo em detrimento de outros, na seleção de determinadas ideias e no negligenciar de 
Dias, G.

outras, no enfatizar um estilo de escrita - particularmente o aforismo - a despeito de outros.

Todos os textos publicados neste dossiê foram atualizados segundo o acordo ortográfico vigente. Não obstante, no caso de alguns vocábulos estrangeiros e outros próprios da filosofia nietzschiana, optamos por não atualizar pela tradução corrente, a fim de conservar a identidade e o contexto histórico do escrito. Para os nomes próprios adotamos a seguinte orientação: os nomes de autores e pessoas foram conservados na grafia original do período, com exceção de alguns já fixados na ortografia atual.

II

A imprensa brasileira do final do século XIX e início do XX recepciona a obra de Nietzsche em revistas, jornais e almanaques de orientação bastante divergentes. Num primeiro momento, nota-se que o filósofo aparece principalmente em diários e periódicos engajados na divulgação de ideias ditas modernas, entre os quais podemos destacar os diários Gazeta de Notícias e Correio da Manhã, as revistas Fon-fon, a Revista de Antropofagia, Festa, a Revista da Semana e, em particular, a revista O Pirralho, periódico literário, político e de humor, fundado por Oswald de Andrade, em 1911, com a intenção de repensar a arte brasileira. Na revista $O$ Pirralho o pensamento de Nietzsche enseja propostas de renovação estética e política, fornece elementos para alavancar uma ruptura com a forma de criar e pensar a arte tradicional, romântica, parnasiana etc. Nessa direção é que Amadeu Amaral publica o texto "O super-homem"; o termo é utilizado no periódico a fim de corroborar a luta pelo civilismo de Rui Barbosa contra a ditadura de Pinheiro Machado.

Entre as diversas referências ao filósofo $O$ Pirralho traz a expressão "nós, os modernos, os supremos, os filhos de Nietzsche", com a qual indica a importância do pensamento nietzschiano para 
a produção dos intelectuais desse período ${ }^{4}$. Ela aponta para os intelectuais posteriormente considerados modernistas, que então começam a se agrupar. $\mathrm{O}$ desconhecido autor da expressão é preciso em suas palavras, indica a quem o texto se dirige em letras garrafais, Ignácio da Costa Ferreira, mais conhecido como Ferrignac, advogado, ilustrador, desenhista, caricaturista e escritor. Com o trabalho intitulado Natureza Dadaísta, participou da Semana de Arte Moderna. Nesse clima cultural que culminará no Modernismo e que pretende, tal como afirma o autor do trecho, "a regeneração estética da terra", Nietzsche vincula-se às mudanças culturais produzidas pelos intelectuais que, nas mais diversas áreas da criatividade, poesia, teatro, música, artes plásticas, buscam uma ruptura com a tradição e a superação dos padrões artísticos da época. Neste horizonte de transição, sua filosofia incide no processo de ruptura e não se limita a uma moda passageira, é antes uma importante fonte de renovação estética. É nessa direção que Oswald de Andrade aponta o livro Amor Imortal, de José Antonio Nogueira, como sendo uma produção de inspiração nietzschiana e algo "novo no nosso meio produtivo", pois "de fato", "não se joga assim Nietzsche à cabeça d'um público habituado a ver estreias pouco complicadas sem ser novo pelo menos". Alinhado com a corrente espiritualista, o autor se vale da ideia da "Volta Eterna" de Nietzsche para pensar uma nova noção de eternidade e imortalidade da alma ${ }^{5}$. Alertando contra esse uso da filosofia de Nietzsche em favor do espiritualismo, Oswald de Andrade afirma que ele se deteve além da conta em Nietzsche, "e pior, [que] em filosofia ficaste a quem dele".

No entanto, do período da Primeira Guerra Mundial adiante são abundantes e controversas as menções a obra de Nietzsche na imprensa de orientação menos progressista e mais conservadora,

4 Edição 238, de 20 de Maio de 1917.

5 NOGUEIRA, José Antonio. (1925). Amor imortal. Narrativas de uma dolorosa iniciação nos mistérios da morte e do além. RJ, $3^{\circ}$ ed. Livraria da Federação Brasileira.

6 ANDRADE, Oswald. O Pirralho, edição 192, 19 de Junho de 1915. 
Dias, G.

seja, por exemplo, na revista católica A Ordem, no jornal Correio Paulistano, bem com diário A Razão, de orientação integralista; onde o chefe do integralismo, Plínio Salgado, declara ver em Nietzsche a violência do individualismo e do egoísmo burguês ${ }^{7}$. Nesses diários e periódicos as referências ao filósofo tendem a associá-lo ao nazifascismo, não raro sua filosofia é interpretada como um instrumento a serviço do imperialismo belicista germânico da época. Muitos de seus textos seguem uma perspectiva reacionária à utilização de sua filosofia realizada por autores como Graça Aranha e Oswald de Andrade. É o caso do texto de Menotti Del Picchia, Schopenhauer e a política, em que o futuro integrante do movimento Verde-Amarelo declara que "as massas populares germânicas vinham sendo trabalhadas por uma filosofia brutal e egoísta, donde ressaltava um pan-germanismo talhado pela vontade de Zaratustra". Assevera ainda uma vez mais a sua posição afirmando que o imperialismo germânico pretendia construir uma raça-superior e que "o método para a consecução" desse objetivo "está todo na velada crueldade do super-homem".

Assim, esses dois fatores, isto é, a renovação estético-cultural e a reação político-religiosa comparecem nas leituras da obra de Nietzsche desde os autores germanistas, como Silvio Romero, Farias Brito, João Ribeiro, Mário Lima etc. Suas divulgações das ideias germânicas suscitarão reações conservadoras, isto é, contrárias à renovação por eles empreendida no panorama da filosofia

7SALGADO, Plínio. Civilizemos a Europa!. A Razão, Fortaleza, 18 de Setembro de 1936. Contra essa reação conservadora, Oswald de Andrade aponta Plínio Salgado como "um autêntico clandestino no Modernismo", procura assim reabilitar Nietzsche afastando-o, no âmbito internacional, das políticas nazifascistas e, no âmbito nacional, de seu político pelo movimento Verde-Amarelo, afirmando que o filósofo "nunca subiria as escadas da Chancelaria do Reich", e "foi sobretudo um grande honesto. Nele se consubstancia historicamente a primeira consciência do homem autônomo que o individualismo iria dar". In Informe sobre o Modernismo. Conferência realizada em 15 de Outubro de 1945, na Unicamp.

8 PICCHIA, Menotti Del. Schopenhauer e a política. Correio Paulistano. São Paulo, 07 de Maio de 1918.

90 | Cad. Nietzsche, São Paulo, v.36 n.1, p. 85-102, 2015. 
no Brasil, na medida em que seu germanismo "abriria uma janela escancarada pela qual entraria "uma rajada de pensamento livre, de cultura moderna que fecundou numerosos espíritos" ".

Tanto que é justamente em reação aos germanistas que aparece o primeiro artigo inteiramente dedicado a uma análise da filosofia de Nietzsche no Brasil, publicado em 1893, por Julio Erasmo, no diário carioca Gazeta de Notícias; texto aqui transcrito. Em seu artigo, o autor condena "as tendências filosóficas de algumas escolas alemãs que estão surgindo", por se mostrarem "preconizadoras do imoralismo". Julga Nietzsche um pensador aristocrático, cínico, autor de teorias perniciosas e em nada autêntico em suas ideias, mas apenas um reprodutor dos gregos e modernos: "Atualmente", diz o autor, referindo-se aos germanistas, "fala-se com insistência sobre Frederico Nietzsche, o chefe do neo-cinismo, ou dos cínicos aristocráticos". Também discorre sobre a biografia do filósofo, fala de sua moral de nobres e plebeus, mostra dificuldades para traduzir termos como übermensch, vertendo por "sobrehomem", entendido como "o tipo produto de rigorosa seleção". Nesse tom reacionário, considera, por fim, que as teorias de Nietzsche são deletérias, perniciosas, deprimentes e perturbadoras da ordem moral.

Em seguida, transcrevemos o texto de Araripe Júnior, no qual o crítico propõe refletir sobre o sentimento trágico do século XIX, encontrando na obra do jovem Nietzsche, A origem da tragédia, a exposição do sentimento trágico moderno, em particular do século XIX, e não do sentimento trágico grego, como se costuma creditar. Publicado no anuário carioca Almanaque Garnier, em 1904, foi reeditado depois na sua Obra Crítica ${ }^{10}$. O texto é significativo porque segue o rumo da renovação estética em curso, considerando o sentimento trágico a base da obra artística do século XX.

9 COSTA, Cruz. Contribuições à História das Ideias no Brasil (O desenvolvimento da filosofia no Brasil e a evolução histórica nacional). Livraria José Olympio Editora, Rio de Janeiro, 1956, p. 297.

10 ARARIPE JR., T. A. Obra Crítica de Araripe Júnior. Rio de Janeiro, Fundação Casa de 
Dias, G.

Temos ainda um poema inédito, de Augusto dos Anjos, bastante breve, porém todo dedicado a Nietzsche, publicado no diário pernambucano $O$ Commércio, em $1905^{11}$. O texto é significativo por se tratar de um poema que não foi incluído na publicação original do livro $E u$, de 1912, e também porque retrata bem seu autor: um poeta pré-modernista, difícil de ser localizado, visto quase sempre "entre o fim da poesia simbolista no Brasil e os primeiros sinais de uma poesia moderna que só nascerá em 1922"12. Nele, o poeta paraibano homenageia o filósofo, discorre sobre sua vida e morte e questiona, de maneira exclamativa, sua vida de pensador, exclusivamente dedicada à construção do pensamento filosófico, embora abalada pela loucura.

A leitura da obra de Nietzsche em favor de uma renovação estética e política, embora neste caso de caráter elitista e conservadora, é ainda mais visível na produção de Elysio de Carvalho. Ele mesmo se definia como um intelectual fiel à filosofia nietzschiana, com a qual julga ter procurado pensar por conta própria a cultura brasileira. Por essa razão, talvez, em resenha crítica dedicada ao seu livro Modernas correntes estéticas na literatura brasileira, publicada pelo diário $O$ Paiz, seja dito que seu autor "é um dos "bons europeus", de Nietzsche", pois "é como "bom europeu" que é crítico do Brasil"’3. Não obstante, na verdade, Elysio estava engajado na defesa dos fundamentos históricos, políticos e estéticos de um nacionalismo radical; seu pragmatismo já anuncia Monteiro Lobato e outros intelectuais defensores da siderurgia e da exploração do petróleo brasileiro ${ }^{14}$. Com seu ideal nietzschiano

Rui Barbosa, volume V 1911 e Anexos, 1971, p. 86-89.

11 Poema disponível no blog Liramundo: https://liramundo.wordpress.com/2012/12/09/ sobre-nietzsche-e-o-tragico-em-augusto-dos-anjos.

12 CARPEAUX, Otto Maria. “Apresentação". In Toda Poesia/Augusto dos Anjos. São

Paulo, 3. Ed. ver. Paz e Terra, 1995, p. 11.

13 O Paiz, Novos Livros, 08 de Agosto de 1907, p. 04.

14 Cf. NUNES, Cassiano. "Elysio de Carvalho e o espírito do seu tempo". In: Obras de Elysio de Carvalho: ensaios. Brasília, Universa-UCB, 1997, p. 13-14.

92 | Cad. Nietzsche, São Paulo, v.36 n.1, p. 85-102, 2015. 
de cultura, no livro $O$ Problema da Cultura, concebe "o niilismo dionisíaco que preconiza o ideal trágico, a cultura estética do eu, o amor fati, a gaia ciência [como] esforço para o estabelecimento de uma civilização verdadeiramente humana" ${ }^{15}$. Entretanto, por trás de seu "niilismo dionisíaco" está "o perfil truculento da alegoria restauradora dos dissidentes: a ideologia do ideal trágico de vida com que se mede o presente emperrado da nação, em contraste com o ufanismo delirante do futuro, marcado pela admiração por todas as formas de poder e de grandeza"16. Prova disso é que na revista América Brasileira, por ele produzida e dirigida, a filosofia de Nietzsche comparece principalmente no contexto dos estudos sobre a formação política e cultural brasileira, sendo o Marques de Pombal interpretado como a "imagem" do "superhomem". Ele dá início a um nacionalismo radical cuja base ideológica se concentra na alegoria do heroísmo, isso explica porque considera que "o Marquês de Pombal é, com efeito, um dos mais lídimos exemplares dessa espécie a que Nietzsche chamou de superhumana"17.

No ensaio Trágica história de um criador de valores, aqui transcrito, de início Elysio destaca a precedência do pensador em relação à sua obra, considerando que o lado mais atraente do estudo das obras de Nietzsche é o próprio filósofo, sua vida, suas vivências, dores e sofrimentos, sua atitude afirmativa diante da vida tal qual ela é e como poderia ser. Contudo, na contramão dos estudos

15 CARVALHO, Elysio. Obras de Elysio de Carvalho: ensaios. Brasília, Universa -UCB, 1997, p. 24.

16 Conforme aponta o estudo de Antonio Arnoni Prado, Itinerário de uma falsa vanguarda, a renovação promovida por Elysio de Carvalho está alinhada "ao conservadorismo elitista da virada do século, cujas ideias definirão uma facção do Modernismo de 22". Ele "antecipa aqui um panorama literário que não ficará apenas no romance e no teatro de Graça Aranha, ou mesmo no descomedido rasgo ufanista de Toda a América, mas irá além, se compararmos, por exemplo, as teses da América Brasileira (1922) com a linha do Movimento Brasileiro, do Manifesto Nhengaçu, da Novíssima ou do ideário do grupo d Lanterna Verde (...). Ver PRADO, Antonio Arnoni. Itinerário de uma falsa vanguarda: os dissidentes, a Semana de 22 e o Integralismo. Prefácio de Sergio Miceli. SP, Ed. 34, 2010, p. 41-49.

17 CARVAlHO, Elysio. Pombal e a civilização brasileira. América Brasileira, n. 14, Rio de Janeiro, Fevereiro de 1923, p. 42.

Cad. Nietzsche, São Paulo, v.36 n.1, p. 85-102, 2015. 
Dias, G.

predominantemente biográficos comum à época, Elysio é um dos primeiros autores brasileiros a tentar uma interpretação dos textos de Nietzsche, para então melhor compreender o filósofo, visto como um pensador de temperamento, conceito este emprestado da filosofia subjetivista ou de confissão (Bekenntnissphilosophie) em oposição à filosofia de conhecimento (Erkenntnissphilosophie), remetidos por ele a Kurt Breysing, um admirador fanático de Nietzsche ${ }^{18}$.

Fábio Luz, escritor anarquista, médico e intelectual atuante na cultura brasileira do momento, critica duramente a renovação estético-cultural de inspiração nietzschiana promovida por Elysio de Carvalho. No texto de sua autoria aqui transcrito, publicado em 1907, no anuário carioca Almanaque do Garnier, o poeta começa apontando Elysio como divulgador das obras de Nietzsche no Brasil, quando então, de fato, apenas poucos conheciam "o autor de Zaratustra". Em seguida, com uma crítica sarcástica e virulenta, sugere que "As nebulosidades de Nietzsche, a sua filosofia egoística e dionisíaca, os símbolos e infinitos parágrafos da Aurora, a Origem da Tragédia e o Anticristo precisavam, como livros santos, como alcorões de novos credos, da interpretação dos textos, e Elysio de Carvalho atirou-se a esse trabalho insano de vulgarizar e popularizar suas obras". Nesse sentido, assevera sua crítica acusando a propaganda feita pelo vulgarizador dos símbolos nietzschianos e seus novos valores morais de ser inútil e perniciosa aos jovens. Por fim, julga Elysio de Carvalho como "um fraco tipo do superhomem, com sua adiposidade, e apesar ou por causa dela tem saúde fraca, nefralgias frequentes, irritabilidade neurastênica, enxaquecas que o tornam intratável quando o acometem. Será um representante man das teorias exóticas do individualismo, do egoísmo sublimado do anarquismo transviado, mas não é um superhomem psiquicamente superior, capaz de vencer e esmagar".

18 LEPENIES, Wolf. As três culturas. São Paulo: Edusp, Vol. 13, 1996, p. 273.

94 | Cad. Nietzsche, São Paulo, v.36 n.1, p. 85-102, 2015. 
Portanto, se de um lado havia quem falasse das ideias estéticas de Nietzsche em favor da renovação, havia de outro quem as mencionasse para reagir politicamente contra essa mesma renovação, a fim de fortalecer a corrente espiritualista, desejosa de retomar e conservar os valores cristãos, sua moral e 'os bons costumes'. É para essa última direção que o texto A estética de Frederico Nietzsche aponta, da autoria do Padre Leonardo Mascello, publicado no Jornal do Recife, a 10 de Novembro de 1911. O autor se mostra motivado a escrever sobre o filósofo por causa das inúmeras publicações a seu respeito, como a biografia trazida ao público por sua irmã, Elisabeth Förster. Contudo, discorre apenas rapidamente acerca da vida do pensador, uma vez que seu objetivo é apontar na sua estética alguns defeitos e equívocos. Passa então a uma abordagem da obra Origens da tragédia, recorre aos trabalhos de Ettore G. Zoccoli e Attillio Corsi. Nessa direção, afirma "que em nenhuma das obras de Nietzsche há continuidade harmônica de exposição ou de investigação, a não ser nas Origens da tragédia, o único livro dele que apresenta um desenvolvimento progressivo de uma teoria, até tornar-se quase um tratado". Alega que os críticos dividem as suas concepções crítico-estéticas em dois períodos: um pro e outro contra Wagner. $\mathrm{O}$ autor mostra certo domínio dos temas da estética do jovem Nietzsche, embora faça dele um devedor das teorias de Schopenhauer e da música de Wagner mais do que de fato teria sido.

Transcrevemos ainda um texto anônimo, com título Block-Notes Mundial, publicado na revista carioca Fon-fon, em 1918. É um texto significativo por ser uma das primeiras leituras empenhadas em afastar as obras de Nietzsche do imperialismo germânico. Além disso, se mostra importante por mencionar a recepção francesa do pensador.

Em seguida, vê-se que a escritora nietzschiana Albertina Bertha foi uma intelectual atuante e renovadora, seja por sua luta contra a hegemonia masculina nos meios literários da época e a favor do voto 
Dias, G.

feminino e do divórcio ${ }^{19}$, seja, também, por sua produção, tanto no sentido de compor romances de inspiração nietzschiana, quanto no sentido de ser a primeira mulher a divulgar e estudar o pensamento do filósofo no Brasil. Em sua conferência realizada no salão nobre do diário carioca Jornal do Commercio, no mês de Agosto de 1914, aqui transcrita, a feminista adverte não ser possível estudar a obra de Nietzsche de maneira fragmentaria, uma vez que "a sua filosofia não obedece a sistemas, não tem ordem, não é catalogada". Daí seguiria, julga a escritora, "a grande dificuldade de ser ele abordado, compreendido e analisado". Faz ainda apontamentos acerca do estilo aforismático do filósofo, considerando que este seria formado por períodos curtos, sintéticos e que muitas vezes nada tem com os antecedentes. Sua conferência seria depois publicada na primeira série de seus Estudos, de 1920, abrindo o livro com o título "Nietzsche". De modo geral, seu estudo sobre o filósofo foi considerado pela crítica como revelador de Nietzsche em nosso meio.

Nele, contudo, a autora nada mais fez do que especular sobre a biografia, a bibliografia e, muito rasteiramente, ratificar alguns preconceitos correntes acerca de algumas ideias já conhecidas da filosofia de Nietzsche na época. Em comparação com autores como Paulo Prado, que menciona o filósofo a fim de com ele corroborar a renovação estética em curso no momento, Albertina Bertha se mostra reacionária, no sentido de considerar que Nietzsche "usa dos mesmos recursos dos ensinamentos cristãos", sendo ele o expoente do mais alto idealismo, em busca da "grande pausa da beleza". Discorre sobre muitos temas de sua filosofia, como a arte, a moral, o niilismo, a mulher, concebe como monista a teoria da vontade de poder.

É nessa direção, justamente, que Lima Barreto, na resenha dedicada ao seu livro Estudos, aqui transcrita, exclama fortemente

19 MARTINS, Anna Faedrich. A produção de autoria feminina: Albertina Bertha e a imprensa periódica. In: Pontos de Interrogação. Vol. 2, n. 1, jan./jun. 2012, p. 44-58.

96 | Cad. Nietzsche, São Paulo, v.36 n.1, p. 85-102, 2015. 
contra o Nietzsche divulgado por Albertina Bertha. Em particular, protesta irritado e de maneira sarcástica contra a sua comparação do conceito do übermensch com o Nirvana búdico e o Paraíso cristão. Contudo, para contrapor-se ao Nietzsche estudado pela feminista, Lima Barreto acusa o filósofo do "flagelo que vem sendo a guerra de 1914", dizendo que ele "deu à burguesia rapace que nos governa uma filosofia que é a expressão de sua ação". Mais ainda, considera que ele "Exaltou a brutalidade, o cinismo, a amoralidade, a inumanidade e, talvez, a duplicidade"20. De fato, Lima Barreto estabeleceu um diálogo tenso com muitos conceitos e ideias de Nietzsche, isso pode ser percebido, em tons diversos, desde as anotações de leituras, artigos, crônicas até a composição de alguns de seus principais personagens de ficção ${ }^{21}$.

O brevíssimo texto de João Ribeiro, $O$ verso, aqui transcrito, publicado em 1923, na revista carioca Fon-fon, expressa a atmosfera de renovação das artes em curso no momento, onde a obra de Nietzsche tem presença constante, como era o caso nas reflexões estéticas do germanista. Tanto é assim que os ensaios de João Ribeiro, publicados no livro Páginas de Estética, de 1905, segundo Elysio de Carvalho manifestam um "gênero tão comum hoje entre os críticos alemães", no qual "Frederico Nietzsche se tornou mestre inexcedível e, ainda mais, o tornou difícil", que, "sem custo [o autor] obteve o que na filosofia nietzschiana se chama a conservação da cultura, entendida como unidade do sentimento, do pensamento e do estilo, como unidade do estilo artístico em todas as manifestações da vida" 22 .

Em seguida, temos o texto Frederico Nietzsche, publicado na revista carioca Fon-fon, em 1933. Embora seja de carácter

20 BARRETO, Lima. Estudos. Gazeta de Notícias. Rio de Janeiro, 26 de Outubro de 1920, 02.

21 FIGUEIREDO, C. Uma corda sobre o abismo: diálogo entre Lima Barreto e Nietzsche. Alea. v. 6 N. 1 Jan./Jun. 2004 p. 159-173, p 01.

22 CARVALHO, Elysio. "João Ribeiro". In: As modernas correntes estéticas na literatura Brasileira. Rio de Janeiro: 1907, p. 289. 
Dias, G.

predominantemente biográfico, ainda assim seu autor, Corrêa Velho, discorre sobre algumas das produções de Nietzsche, julga que ele deixou uma obra inacabada e de aparência caótica. Destaca como obra prima "Assim falava Zaratustra", a qual considera de uma inigualável beleza lírica, e mesmo como um dos mais famosos poemas conhecidos em prosa.

Na sequência, transcrevemos o texto Nietzsche e Getúlio Vargas, publicado no diário carioca A Noite, em 1939. Trata-se de uma entrevista feita por Alvoro de Las Casas para o jornal chileno $E l$ Mercurio, reeditada no jornal carioca pelo jornalista Ernani Reis. $\mathrm{Na}$ entrevista, Nietzsche aparece como mentor intelectual de Getúlio Vargas, sendo o único filósofo a escapar ao naufrágio dos ídolos, conforme dito pelo próprio Vargas. Em pleno regime do Estado Novo, considera-se que a feição nietzschiana perdura e domina no espírito do ditador brasileiro, ensejando semelhanças entre sua filosofia e o governo autoritário de Vargas.

Com essa mesma tonalidade político-reacionária, temos o texto Nietzsche triunfante, de Hamilton Barata, publicado em 1940, no jornal carioca Gazeta de Notícias. Nele, seu autor procura ler algumas ideias da filosofia de Nietzsche segundo o contexto político brasileiro do momento, aproximando o filósofo a Getúlio Vargas, para assim legitimar seu governo autoritário e seu posicionamento internacional diante da Guerra ora em curso na Europa. A utilização política das ideias do autor de Zaratustra em favor do governo Vargas é a tônica principal do texto, sendo Nietzsche interpretado como o terrível profeta da dominação e da força máscula cuja lei é a sua própria vontade de potência.

Nessa mesma senda, temos o texto Nietzsche em voga, publicado em 1941 pela revista de orientação católica $A$ Ordem, no Rio de Janeiro. Seu autor, o padre Carlos Borromeu, considera que Nietzsche teria negado a moral tradicional, concebendo em seu lugar outra, porém imoral e brutal; se mostra assim reacionário, no sentido de pretender retomar e conservar a moral e os valores da 
religião cristã, acusando o filósofo de ser responsável pela Guerra ora em curso na Europa.

De maneira semelhante, temos ainda o artigo Frederico Nietzsche, do modernista Renato Almeida, publicado no diário carioca $A$ Manhã, em 1944. Tal como outros publicados no mesmo ano, vem a público a propósito da celebração do centenário de nascimento do filósofo. Alegando identificar certo irracionalismo e mistíssimo no pensamento de Nietzsche, Renato Almeida procura associar sua obra à política nazista. Em sua abordagem, se vale de comentadores como Spengler e Simmel, reage contra a utilização da filosofia de Nietzsche em favor da renovação estética colocada em curso pelo autor modernista Graça Aranha.

Na contramão da insistente associação da obra de Nietzsche com políticas autoritárias, seja de Hitler, Mussolini ou Vargas, temos o artigo $O$ centenário de Nietzsche e o nazismo, de Evaristo Marais Filho, publicado no jornal carioca Diário de Notícias, em 1945. Em oposição às abordagens reacionárias, tão comuns à época, que teimam em associar Nietzsche com o nazifascismo, adiantando o que posteriormente autores como Antonio Candido fará, Evaristo procura tirar algumas conclusões metodológicas e políticas da obra do filósofo contrárias ao espírito nazista. Acusa ainda os suspeitos e apressados divulgadores de sua filosofia, como Will Durant, de injustamente situá-lo como mandante espiritual dos crimes praticados pelos sanguinários bandidos nazifascistas ${ }^{23}$.

Nessa mesma direção segue o texto Nietzsche ainda cresce, de Cleto Seabra Veloso, publicado no jornal carioca Diário de Notícias, em 1945, no qual seu autor procura afastar a obra de Nietzsche das apropriações nazistas.

Por fim, dentro da chave de leitura reacionária, transcrevemos o texto Nietzsche, filósofo da Alemanha nazista, de autoria de João

23 Importa mencionar que essa divulgação, feita na História da filosofia, de Will Durant, foi traduzida por Monteiro Lobato e Godofredo Rangel. 
Dias, G.

Scapino, publicado no jornal carioca Diário de Notícias, em 1945. Seu autor julga Nietzsche um mostro e filósofo por excelência da Alemanha nazista. Nesse sentido, destaca a teoria da "Vontade do Poder" como sendo um fluxo vital e que serviu como fonte de inspiração a Hitler e Mussolini, sugerindo a crueldade, a agressividade e a política de expansão da Alemanha nazista.

De fato, desde o final do século XIX e início do XX não faltou quem censurasse a formação de uma opinião unilateral e falsa sobre a obra e a personalidade de Nietzsche; denunciando, por exemplo, sua irmã, Elisabeth Förster, de fundar sua glória sobre bases ilegítimas. Como bem admitiu o modernista Sérgio Buarque de Holanda, havia "razão nessa censura, partida principalmente dos homens de Esquerda, dos socialistas". Não obstante, ele mesmo também questiona: "Mas seria, por ventura menos ilegítima e menos superficial a atitude desses mesmos homens quando pretendiam criar um Nietzsche à sua imagem?"24.

\begin{abstract}
This paper aims to present eighteen texts on Nietzsche published in the Brazilian press in the period from 1893 to 1945. These studies show that two factors of Brazilian culture that period guide the philosopher's reading: the aesthetic and cultural renewal and the political reaction religious. All texts transcribed sequence following the chronological order of their publications. Keywords: Nietzsche - Reception - Brazil - Imprensa - Jornal do Commercio - Gazeta de Notícias - Fon-fon - O Commercio - Almanaque do Garnier - América Brasileira - Jornal do Recife - A Noite - Diário de Notícias - A Manhã
\end{abstract}

24 HOLANDA, Sérgio, B. Elisabeth Förster - Nietzsche. Folha da Manhã. São Paulo, 19 de Dezembro de 1935, p. 06.

100 I Cad. Nietzsche, São Paulo, v.36 n.1, p. 85-102, 2015. 


\section{referências bibliográficas}

ALMEIDA, Renato. Frederico Nietzsche. In: A Manhã. Rio de Janeiro, 15 de Outubro de 1944.

ANJOS, Augusto. Soneto. In: O Commércio, Pernambuco, 19 de maio de 1905.

ANÔNIMO. Block-Notes Mundial. In: Fon-fon, Rio de Janeiro, Fevereiro de 1918.

ARARIPE JR., T. A. Obra Crítica de Araripe Júnior. Rio de Janeiro, Fundação Casa de Rui Barbosa, volume V 1911 e Anexos, 1971.

BARATA, Hamilton. Nietzsche triunfante. In: Gazeta de Notícias. Rio de Janeiro, 03 de Julho de 1940.

BARRETO, Lima. Estudos. In: Gazeta de Notícias. Rio de Janeiro, 26 de Outubro de 1920.

BARRETO, Tobias. Nem filósofo nem crítico. In: A Província, Pernambuco, 10 de Março de 1876.

BERTHA, Albertina. Nietzsche. In: Estudos. $1^{\mathrm{a}}$ série. Rio de Janeiro: Jacintho Ribeiro dos Santos Editor, 1920.

BORROMEU, Carlos. Nietzsche em voga. In: A Ordem. Rio de Janeiro, Abril de 1941.

CANDIDO, Antônio. Literatura e sociedade. Rio de Janeiro, Ouro Azul, $12^{\circ}$ ed., 2011.

CARPEAUX, Otto Maria. Apresentação. In: Toda Poesia/Augusto dos Anjos. São Paulo, 3. Ed. ver. Paz e Terra, 1995.

CARVALHO, Elysio. Obras de Elysio de Carvalho: ensaios. Brasília, Universa -UCB, 1997.

Pombal e a civilização brasileira. In: América Brasileira, n. 14, Rio de Janeiro, Fevereiro de 1923.

COSTA, Cruz. Contribuições à História das Ideias no Brasil (O desenvolvimento da filosofia no Brasil e a evolução histórica nacional). Livraria José Olympio Editora, Rio de Janeiro, 1956.

ERASMO, Julio. O neo-cinismo. In: Gazeta de Notícias. Rio de Janeiro, 20 de Maio de 1893.

FILHO, Evaristo Morais de. O centenário de Nietzsche e o nazismo. In: Notícias. Rio de Janeiro, 04 de Fevereiro de 1945.

FIGUEIREDO, Carmem, L. N. Uma corda sobre o abismo: diálogo entre Lima Barreto e Nietzsche. Alea. v. 6 N. 1 Jan./Jun. 2004 p. 159-173.

HOLANDA, Sérgio, Buarque de. Elisabeth Förster - Nietzsche. In: Folha da Manhã. São Paulo, 19 de Dezembro de 1935.

LEPENIES, Wolf. As três culturas. São Paulo, EdUSP, Vol. 13, 1996.

LUZ, Fábio. Elysio de Carvalho. In Almanaque do Garnir. Rio de Janeiro, 1907.

Cad. Nietzsche, São Paulo, v.36 n.1, p. 85-102, 2015. | 101 
Dias, G.

MARTINS, Anna Faedrich. A produção de autoria feminina: Albertina Bertha e a imprensa periódica. Pontos de Interrogação. Vol. 2, n. 1, jan./jun. 2012, p. 44-58.

MASCELLO, Leonardo. A estética de Frederico Nietzsche. In: Jornal do Recife. Pernambuco, 10 de Novembro de 1911.

NOGUEIRA, José Antonio. Amor imortal. Narrativas de uma dolorosa iniciação nos mistérios da morte e do além. RJ, $3^{\circ}$ ed. Livraria da Federação Brasileira, 1925.

NUNES, Cassiano. Elysio de Carvalho e o espírito do seu tempo. In: Obras de Elysio de Carvalho: ensaios. Brasília, Universa-UCB, 1997.

PICCHIA, Menotti Del. Schopenhauer e a política. Correio Paulistano. São Paulo, 07 de Maio de 1918.

PRADO, Antonio Arnoni. Itinerário de uma falsa vanguarda: os dissidentes, a Semana de 22 e o Integralismo. Prefácio de Sergio Miceli. SP, Ed. 34, 2010.

REIS, Ernani. Nietzsche e Getúlio Vargas. In: A Noite. Rio de Janeiro, 21 de Junho de 1939.

RIBEIRO, João. O verso. In: Fon-fon. Rio de Janeiro, Dezembro de 1923.

SALGADO, Plínio. Civilizemos a Europa!. A Razão, Fortaleza, 18 de Setembro de 1936.

SCAPINO, Joao. Nietzsche, o filósofo da Alemanha nazista. In: Diário de Notícias. Rio de Janeiro, 07 de Outubro de 1945.

SILVA JR, Ivo da. "Nietzsche e a cultura brasileira". In: Em busca de um lugar ao sol: Nietzsche e a cultura alemã. São Paulo: Discurso Editorial, 2007.

VELOSO, Seabra Cleto. Nietzsche ainda cresce. In: Diário de Notícias. Rio de Janeiro, 21 Outubro de 1945.

VELHO, Corrêa. Frederico Nietzsche. In: Fon-fon. Rio de janeiro, 7 de Outubro de 1933.

Web Site

BLOG LIRAMUNDO. Pesquisa sobre Augusto dos Anjos. Disponível em https://liramundo. wordpress.com/2012/12/09/sobre-nietzsche-e-o-tragico-em-augusto-dos-anjos/

SITE UOL. Nietzsche: aqui e lá. Entrevista com Scarlett Marton realizado por João Neto. In Revista Filosofia, Editora Escala. Disponível em http://filosofiacienciaevida. uol.com.br/ESFI/Edicoes/75/artigo271728-3.asp.

Artigo recebido para publicação em 20/01/2015.

Artigo aceito para publicação em 22/02/2015.

102 | Cad. Nietzsche, São Paulo, v.36 n.1, p. 85-102, 2015. 